\title{
Conselho tutelar e política eleitoral: a formação da carreira política partidária a partir da função de conselheiro tutelar
}

\author{
Guardianship council and electoral policy: the formation of the party career from the role of
} guardianship adviser

Consejo de tutela y política electoral: la formación de la carrera partidista desde el rol de asesor de tutela

\begin{abstract}
Resumo
O artigo versa sobre a formação da carreira política partidária a partir do exercício da função pública de conselheiro tutelar. Esse apanhado analítico foi inscrito a partir de dois estudos de caso, ocorrido no Conselho Tutelar (CT) do município de Horizonte, Estado do Ceará. Em tese, esse espaço social - Conselho Tutelar - cria "pontes” para a carreira política partidária, permitindo que outsiders ganhem visibilidade pública que, sem esse recurso, não seria possível adentrar o espaço político partidário. Assim, para essa reflexão, trouxemos as trajetórias de dois cidadãos ditos "comuns" pela sociedade civil, que adentrou o espaço tutelar e a partir daí galgou sua carreira política partidária trabalhando os elementos contidos no campo tutelar. A observação direta e as entrevistas foram às metodologias utilizadas para o apanhado empírico. O artigo conclui que, através de táticas colocadas em prática por qualquer cidadão que adentre o espaço tutelar, da maneira como esse espaço institucional está desenhado, favorece a formação das carreiras políticas partidárias.
\end{abstract}

Palavras-chave: Conselho tutelar; Carreira política partidária; Campo político.

\begin{abstract}
The article deals with the formation of the party's political career from the exercise of the public function of tutelary councilor. This analytical overview was inscribed from two case studies, which took place at the Guardianship Council (CT) in the municipality of Horizonte, State of Ceará. In theory, this social space - Guardianship Council creates "bridges" for the party's political career, allowing outsiders to gain public visibility that, without this resource, it would not be possible to enter the party's political space. Thus, for this reflection, we bring the trajectories of two citizens called "ordinary" by civil society, who entered the tutelary space and from there climbed their party political career working the elements contained in the tutelary field. Direct observation and interviews were the methodologies used for the empirical survey. The article concludes that, through tactics put into practice by any citizen who enters the tutelary space, the way this institutional space is designed favors the formation of political party careers.
\end{abstract}

Keywords: Guardianship council; Party political career; Political field.

\section{Resumen}

El artículo trata de la formación de la carrera política del partido a partir del ejercicio de la función pública de concejal tutelar. Este repaso analítico se inscribió a partir de dos estudios de caso, que se llevaron a cabo en el Consejo de Tutela (CT) en el municipio de Horizonte, Estado de Ceará. En teoría, este espacio social - Consejo de Tutela - crea "puentes" para la carrera política del partido, permitiendo que los forasteros ganen visibilidad pública que, sin este recurso, no sería posible ingresar al espacio político del partido. Así, para esta reflexión, traemos las trayectorias de dos ciudadanos llamados "ordinarios" por la sociedad civil, quienes ingresaron al espacio tutelar y desde allí ascendieron su carrera política partidaria trabajando los elementos contenidos en el ámbito tutelar. La observación directa y las entrevistas fueron las metodologías utilizadas para la encuesta empírica. El artículo concluye que, a través de tácticas puestas en práctica por cualquier ciudadano que ingrese al espacio tutelar, la forma en que se diseña este espacio institucional favorece la formación de carreras de partidos políticos.

Palabras clave: Consejo de tutela; Carrera política del partido; Campo político. 


\section{Introdução}

Este artigo caminha através das discussões envolvendo dois estudos de caso, com a existência de elementos e nexos semelhantes, vislumbrando uma análise das ações dos conselheiros tutelares para a formação da sua carreira política partidária ocorrida no município de Horizonte, Estado do Ceará. Ele percorre através de três discussões: primeiramente, a idéia de “carreira política partidária”, que no geral ocorre entre as famílias mais abastadas em termos de capital econômico e cultural nas cidades do Estado do Ceará. Em verdade, somos cônscios da existência do poder político dessas famílias que além de estarem envolvidas historicamente nas disputas políticas locais, exercem a função e o mando de grande parte dos cargos públicos mais prestigiosos. Dentre esses cargos mais prestigiosos, há, portanto, uma hierarquia dos cargos, tendo em vista que os políticos atribuem pesos a determinadas funções. Ao longo do tempo, essa visão também foi incorporada pela sociedade civil. Como exemplo simbólico da hierarquia social dos cargos disputados está a de vereador da cidade e a de prefeito municipal. Visto dessa forma, o campo político possui uma carreira hierárquica a partir do peso simbólico conferido a função pública.

De modo geral, tem-se na representação social ${ }^{1}$ dentro do campo político, a idéia de que a função pública de vereador é de peso menor do que a de prefeito municipal, muito embora saibamos que é conferido legalmente a essas funções públicas o mesmo peso de decisão, mesmo com diferentes atribuições legais, por exemplo, entre o poder executivo, legislativo e judiciário. Ainda sob esse olhar, é como se quem estivesse na escala menor da pirâmide social fosse necessário, para ascender ao cargo majoritário do executivo municipal, passar pela função de vereador, fato esse contido nos julgamentos dos diálogos cotidianos e que muito interessam a quem está especificamente exercendo esse poder.

Essa busca pelo poder, já evocada por Rousseau (1989), é sede existente por todo indivíduo em todas as camadas sociais $^{2}$. Se a vontade de ascender socialmente e ter poder é algo presente na vontade dos cidadãos, logo observa-se uma grande disputa por esses cargos. Ainda dentro dessa visão, e diante de uma sociedade onde as posições de poder sempre estiveram historicamente nas mãos de grandes famílias, ditas "coronelistas” (Leal, 2012) que se utilizam do denominado “voto de cabresto" para poder manter-se e perpetuar-se no poder, fica difícil imaginar que um cidadão da camada menos favorecida possa adentrar esse espaço tão restrito e competitivo.

Para o entendimento do "trampolim" do CT para a carreira política partidária, utilizaremos os conceitos de Bourdieu (1989) denominado de campo social (especificamente campo político) e capital (nas suas modalidades simbólica, social e político) para entender esta problemática. O conceito de campo social é importante para que seja possível explicar a relação entre a atuação do agente enquanto conselheiro tutelar e sua atuação enquanto pretenso político profissional, convertendo o capital adquirido no campo (relativo à assistência prestada no CT) para utilizar em outro (o campo político propriamente dito). E os capitais conferem importância por serem propriedades possuídas pelo agente tutelar que lhe dão poder dentro do campo. Por exemplo, no conjunto das relações estabelecidas pelo conselheiro, seja com as pessoas assistidas pelo CT, seja com os políticos com mandatos eletivos ao criar laços e redes de interesses mútuos.

Na teoria bourdieziana (1981:38), campo político,

[...] é definido como um espaço relativamente autônomo, dependente de um universo de regras, crenças e papéis próprios. É o lugar em que se geram - na concorrência entre os agentes que nele se acham envolvidos - produtos políticos, problemas, programas, análises, comentários, conceitos, acontecimentos, entre os quais os cidadãos comuns, reduzidos ao estatuto de "consumidores", devem escolher.

\footnotetext{
${ }^{1}$ Compreende as representações sociais como categorias de pensamento que expressam a realidade, explicam-na, justificando-a ou questionando-a. São conteúdos de pensamento que traduzem a realidade e são por ela traduzidos (Moscovici, 1978). E têm, no dizer de Ângela Therrien (1998: 33), uma função constitutiva da realidade na qual a maioria das pessoas se movimenta. Moscovici (1978: 25) afirma que toda representação é composta de figuras e de expressões socializadas, o que nos remete aos processos sociais de interação como a base para a formulação das representações sociais.

${ }^{2}$ Rousseau (1989) afirma que qualquer cidadão possui interesse pelo poder. Ao viver em uma sociedade desigual, estratificada entre quem manda e quem obedece é fato que os sujeitos querem posições na esfera social que lhe confira respeito e poder.
} 
Os conselheiros tutelares que conseguiram alçar ao posto de vereador municipal eram pessoas da comunidade sem relação direta com a política partidária local, ou, suas ações orbitavam perifericamente o campo político. Contudo, como veremos a frente, a ocupação dessa função fez com que, esses sujeitos, verdadeiros outsiders, ${ }^{3}$ ganhassem visibilidade pública por estarem em constante "movimentação" com os poderes constituídos, isto é, o legislativo, executivo e judiciário. Decerto, essa posição lhes possibilitaram um reconhecimento simbólico, ou capital simbólico, que não possuíam.

O capital simbólico funciona, conforme explica em Le sens pratique, como "um crédito, mas no sentido mais amplo do termo, ou seja, uma espécie de adiantamento, de desconto, de promissória" que os membros de um grupo atribuem somente àqueles que - em razão de sua posição, do trabalho que eles executam para mantê-lo - lhe fornecem o maior número de garantias (Catani, 2017, p. 110).

Esse poder simbólico que os conselheiros passaram a gozar foi oriundo do trabalho que desenvolviam e da função pública que exerciam. A aproximação com a população e suas atribuições tutelares próximas de pessoas que possuem um forte capital político como o é, por exemplo, os políticos com mandatos eletivos, fez com que acumulasse um "crédito" que só foi possível através do CT.

Como hipótese geral afirma-se que o campo tutelar, para aqueles que buscam seguir a carreira política partidária, interfere na estrutura hierarquizada do poder político local/municipal. Dessa forma, percorremos a seguinte indagação: ser conselheiro tutelar é trampolim dos pobres com pouco capital simbólico para a função da sua carreira política partidária? Ou já é um "plus" para quem já está atuando na política formal, ainda que perifericamente?

Em verdade, o Conselho Tutelar possibilita, como veremos, através da visibilidade pública e do contato intenso com famílias vulneráveis a criação de um capital simbólico que pode ser revestido em capital político caso queira adentrar o universo da carreira política partidária. Ele proporciona "atalhos" ou "pontes" ao estar em contato com pessoas que se veem em situações de debilidade emocional que, sendo agenciadas, pode se revestir num grande potencial agregador de capital social e, posteriormente, capital político, ou, em outras palavras, em votos.

Esta hipótese poderá ser comprovada a partir da exploração, num esforço de sistematização, metodologicamente, desses dois estudos de caso que ocorreram na cidade de Horizonte, Estado do Ceará. Primeiro, de um cidadão conselheiro tutelar eleito vereador no ano de 2012. E o outro, por sua vez, eleito no último pleito em novembro de 2020. Através da observação direta e, principalmente, das entrevistas foi possível encontrar os sentidos, bem como os meandros das ações colocados em prática para a obtenção dos objetivos almejados.

Dessa forma, o artigo está dividido da seguinte maneira: a primeira sessão apresenta o espaço Conselho Tutelar (CT) como um campo com elementos específicos (autônomo, produtor de laços e redes de apoio e afetos) conjugados com táticas ${ }^{4}$ que lhes possibilitarão a emergência de caminhos possíveis para "furar" a barreira no qual só alguns poucos, ao longo da história, gozam do seu usufruto. Na segunda, por sua vez, temos a exploração dos dois casos e o percurso utilizado por eles para chegar ao poder, no caso, ser eleito a função pública no legislativo municipal. A última parte trará uma reflexão, denominada de "tensionamento" do Conselho Tutelar e as possibilidades a ele conferidas para a formação da carreira política partidária.

\footnotetext{
${ }^{3}$ Howard S. Becker (2008) a partir dos estudos da sociologia do desvio, vai formular os movimentos ou representações daquilo que é tido como "normal” ou ações e representações que estão fora da norma. Dessa forma, os conselheiros tutelares que não possuem histórico de atuação política partidária, nem em movimentos sociais, são considerados aqui outsiders porque são pessoas que não conviviam no meio político partidário.

${ }^{4}$ Para D'Certeau (2014) “tática” é "um cálculo que não pode contar com um próprio, nem portanto com uma fronteira que distingue o outro como totalidade visível. [...] pelo fato de seu não lugar, a tática depende do tempo, vigiando para "captar no voo" possibilidades de ganho. O que ele ganha, não o guarda. Tem que constantemente jogar com os acontecimentos para os transformar em "ocasiões". Sem cessar, o fraco deve tirar partido de forças que lhe são estranhas. [...] muitas práticas cotidianas (falar, ler, circular, fazer compras ou preparar as refeições, etc) são do tipo tática. E também, de modo mais geral, uma grande parte das "maneiras de fazer": vitórias do "fraco" sobre o mais "forte" (os poderosos, a doença, a violência das coisas ou de uma ordem etc.), pequenos sucessos, artes de dar golpes, astúcias de "caçadores", mobilidades da mão de obra, simulações polimorfas, achados que provocam euforia, tanto poéticos quanto bélicos $(45-46)$.
} 


\section{Metodologia}

A metodologia são os caminhos trilhados para se chegar aos dados empíricos e, por isso, se configura numa etapa muito importante da pesquisa. Como ela foi desenvolvida a partir da aproximação de agentes sociais (DONZOLET, 2001), se deu de maneira extensiva ao longo de outras pesquisas que forem sendo desenvolvidas, por exemplo, no Mestrado Acadêmico em Sociologia da Universidade Estadual do Ceará (UECE) 5 .

Os dados obtidos nesse apanhado empírico ocorrem a partir do mês de maio do ano 2021. Obteve-se em diferentes lugares, uma vez que os atores são figuras públicas de grande movimentação diária ${ }^{6}$. Dito isso, estivemos por diversas vezes com os sujeitos realizando entrevistas abertas para entender a disposição, ações e táticas que foram colocadas em prática para alcançar os objetivos almejados.

Ela se faz eminentemente qualitativa, como bem pontua Minayo (2018):

[...] é preciso afirmar que o objeto das Ciências Sociais é essencialmente qualitativo. A realidade social é a cena e o selo do dinamismo da vida individual e coletiva com toda a riqueza de significados dela transbordante. Essa mesma realidade é a mais rica que qualquer teoria, qualquer pensamento e qualquer discurso que possamos elaborar sobre ela. Portanto, os códigos das ciências que por sua natureza são sempre referidos e recortados são incapazes de conter a totalidade da vida social (p. 14).

Para a teórica, por mais esforço intelectual que façamos para dar sentido e significado as tramas das relações que são orquestrados no cotidiano, sempre estaremos próximos da realidade e nunca com a realidade em tela. Dessa forma, nosso esforço em pintar o percurso da formação da carreira política partidária dos conselheiros tutelares se configuram "num conjunto de expressões humanas constantes nas estruturas, nos processos, nas representações sociais, nas expressões da subjetividade, nos símbolos e significados" (Minayo, 2018, p.14).

Dito isso, o que se propõe - o entendimento das manifestações da formação da carreira política partidária - é mutável como é a vida social. O desenvolvimento desse objetivo dos membros do CT, se faz como um processo. Processo esse que vai ganhando novos contornos e elementos a partir das modificações que ocorrem na sociedade. E o Conselho Tutelar (CT) e os interesses dos conselheiros não estão imunes ao que ocorre na vida social.

Foram utilizados dois estudos de caso que ocorreram em um CT localizado, isto é, no Conselho Tutelar do município de Horizonte, Estado do Ceará. Eles dão visibilidade a um fenômeno social ${ }^{7}$ que vem ocorrendo nos demais CTs que existem nos municípios do país. Para ampliar a confirmação desse fenômeno social, foi realizada uma sondagem nos municípios da região metropolitana de Fortaleza, Estado do Ceará, sobre o quantitativo de conselheiros tutelares que dispuseram seu nome como candidato no último pleito a eleição proporcional ao cargo eletivo de vereador.

Salienta-se que nesse período, no que diz respeito aos CTs da região metropolitana de Fortaleza, diante do cenário da pandemia, a obtenção de quantos conselheiros tutelares dispôs seu nome ao cargo de vereador na última eleição política partidária, foi realizado através de ligações telefônicas ${ }^{8}$.

\footnotetext{
${ }^{5}$ Desenvolvo pesquisas sobre o espaço do Conselho Tutelar (CT) desde as graduações de Ciências Sociais (UFC), Serviço Social (UECE), Pedagogia (FIC), bem como os Mestrados em Sociologia (PPGS/UECE), Avaliação de Políticas Públicas (PPGAPP/UFC) e Educação (PPGE/UFC). E, agora, no Doutorado em Ciências Sociais (PGCS/UFES).

${ }^{6}$ Quando mencionamos a expressão, “movimentação diária”, estamos querendo dizer que os atores dessa pesquisa, por serem agentes públicos, ou seja, por serem vereadores do município de Horizonte, Estado do Ceará, possuem múltiplas atividades durante um único dia. Essa caraterística de vida fez com que as entrevistas fossem realizadas em lugares, dias e horários diferentes, quando os mesmos possuíam tempo para discorrer sobre as disposições utilizadas na configuração da sua formação da carreira política partidária.

${ }^{7}$ Uma pesquisa social a partir de um fenômeno social só existe quando ele é uma problemática na vida cotidiana, ou seja, na vida prática, afirma Minayo (2016). Por isso, a formação da carreira política partidária dos conselheiros se configura como um fenômeno social porque é uma problemática que está ocorrendo na atualidade e necessita de estudos para o entendimento desse fenômeno.

${ }^{8}$ Os dados obtidos nessa pesquisa estarão descritos ao longo do desenvolvimento da leitura.
} 
Além disso, fizemos uso de leituras que versam sobre o universo de instituições participativas (IPs), como é o caso do CT. Mas sempre lembrando que esse espaço, diferentemente de outros IPs, possui suas características específicas, algo que sempre deve ser pontuado em qualquer estudo que o envolva.

\section{Conselho Tutelar: Campo Político de Possibilidades}

Os Conselhos Tutelares (CTs) foram criados a partir da implantação do Estatuto da Criança e do Adolescente (ECA) na década de 1990. Fruto de muitas lutas sociais, o ECA $/ 90^{9}$ é um instrumento que busca horizontalizar direitos as crianças e adolescentes que até então se viam sob o julgo dos ditames adultocêntricos (Priore, 2007). Agora esses Sujeitos de Direitos passam a ter um lugar social diferenciado (Pinheiro, 2006) nas instituições públicas do Estado, na sociedade civil e na Família.

Para a concretização desse novo cenário conferido à criança e ao adolescente, foi necessária a criação de um órgão que protegesse os direitos e deveres dessa nova representação social (Moscovici, 1978). Logo, criaram-se os CTs que têm a função de promover e garantir esses direitos e deveres. E para colocar as normativas do ECA/90 na prática esse órgão utiliza-se de inúmeros instrumentos de atuação no cotidiano infanto-juvenil.

Um desses elementos para poder efetivar a promoção da garantia dos direitos é a autonomia administrativa de atuação, que significa, entre outras coisas, não depender da autorização de ninguém - nem do Prefeito, Vereador, Juiz ou qualquer outro órgão - para pôr em prática aquilo que lhe é atributivo e nem ser interrompido por qualquer ente externo que venha prejudicar sua ação tutelar (Brasil. Lei n 8.069, 1990, art. 95, 101 (I a IV), 129 (I a VII) e 136).

Assim, levando em consideração que o CT possui sua autonomia de atuação legal, este se reveste de prerrogativas constitucionais que o credenciam tramitar nos mais diferentes órgãos e instituições com vistas a garantia e a aplicação do Estatuto da Criança e do Adolescente (ECA/90) em qualquer situação onde os Sujeitos de Direitos (Pinheiro, 2006) possam ou tenham suas garantias constitucionais violadas.

Portanto, esse órgão, além da prerrogativa institucional elencada acima possui outros elementos que precisam ser entendidos a partir dos sujeitos que adentram o campo tutelar. Assim, indagações pulsavam para saber quem eram esses sujeitos que adentravam esse espaço formando o colegiado: a) Quem são esses cidadãos que se submetem ao cargo de conselheiro tutelar, e por que se submetem? B) Será que verdadeiramente a submissão ao cargo está ligada diretamente a defesa dos direitos das crianças e dos adolescentes? C) Que histórico de atuação na defesa das crianças e dos adolescentes esses cidadãos que se submetem ao cargo de conselheiro tutelar possuem?

Tendo em vista que o que move a economia local dos municípios do Estado do Ceará advém dos recursos do poder público municipal, assim como os demais cargos públicos, o cargo de conselheiro tutelar está contido neste panorama contextual. Fato esse comprovado quando indagados o que faziam antes de tornarem conselheiros tutelares, deram ênfase a afirmação de que se candidataram ao cargo em situação de desemprego ou emprego informal (Antunes, 2000). Assim, a eleição ao cargo de conselheiro tutelar tornara-se uma oportunidade de adquirir ocupação mesmo que por tempo determinado ${ }^{10}$.

Outra característica dos candidatos a conselheiros tutelares é que não possuíam, antes de elegerem-se para a função, experiência ${ }^{11}$ direta com a questão social $($ Netto, 2008) que envolve a criança e o adolescente. Essa realidade contraria a

\footnotetext{
${ }^{9}$ Antes da implantação do Estatuto da Criança e do Adolescente (ECA/90), tínhamos em vigência no país o Código de Menores (1979), onde crianças e adolescentes eram tratados com sujeitos inferiores, não possuindo prioridades nas ações e políticas públicas do Estado, na sociedade civil e no convívio intrafamiliar.

${ }^{10}$ A Lei $n^{\circ}$ 12.692/12 alterou as regras para as eleições ao cargo de Conselheiro Tutelar, entre outros dispositivos de cunho administrativo. Através desta ficou estabelecido que a eleição para a escolha dos membros do CT passa a ocorrer em um único dia em todos os municípios do país, isto é, unificou-se o dia da eleição que ocorrerá no primeiro domingo do mês de outubro pós ano da escolha do Presidente da República do Brasil.

${ }^{11}$ Imagine um espaço como é o Conselho Tutelar onde ocorrem inúmeras violações de direitos a criança e adolescente e os agentes tutelares - antes de serem conselheiros tutelares - não possuíam nenhum contato com criança e adolescentes? Como podemos vislumbrar que o trabalho que será desenvolvido estará em
} 
resolução n 170 do Conselho Nacional dos Direitos das Crianças e dos Adolescentes (CONANDA) promulgado no dia 10 de dezembro de 2014, bem como em anos anteriores, de que é necessário para concorrer ao cargo de conselheiro tutelar "experiência na promoção, proteção e defesa dos direitos da criança e do adolescente".

Em verdade, foi apenas na condição de membros do colegiado que passaram a ter contato com relações em "inconformidade" com a norma familiar (Costa, 1989) e societária de crianças e adolescentes. Anteriormente, os conselheiros tutelares em questão - do Conselho Tutelar do Município de Horizonte - nesta pesquisa exerciam, o primeiro, o trabalho como vendedor ambulante de produtos variados, como roupas, calçados e demais tipos de vestimentas. E o segundo, por sua vez, como moto taxista, realizando viagens entre o centro da cidade do município de Horizonte/CE para os distritos ou mesmo para outras cidades adjacentes.

A cidade de Horizonte, no Estado do Ceará, dista cerca de 47 km da Capital do Ceará, Fortaleza. Compõem o cinturão geográfico denominado de região metropolitana de Fortaleza (RMF) em conjunto com 19 municípios atualmente. A criação da região metropolitana ocorreu no ano de 1973, compondo a capital, Fortaleza, mais os municípios de Caucaia, Maranguape, Pacatuba e Aquiraz. Foi criada a partir de um movimento nacional que institui as nove primeiras ${ }^{12}$ regiões metropolitanas do Brasil. Só em 1999, a cidade de Horizonte, mais três outras cidades, isto é, Pacajus, Chorozinho e São Gonçalo do Amarante foram incluídas na RMF. Para saber a distância entre as cidades e a capital e a disposição dos municípios que compõem a Região Metropolitana de Fortaleza (RMF), geograficamente, veja a Figura 1 a seguir.

Figura 1: Região Metropolitana de Fortaleza (RMF).

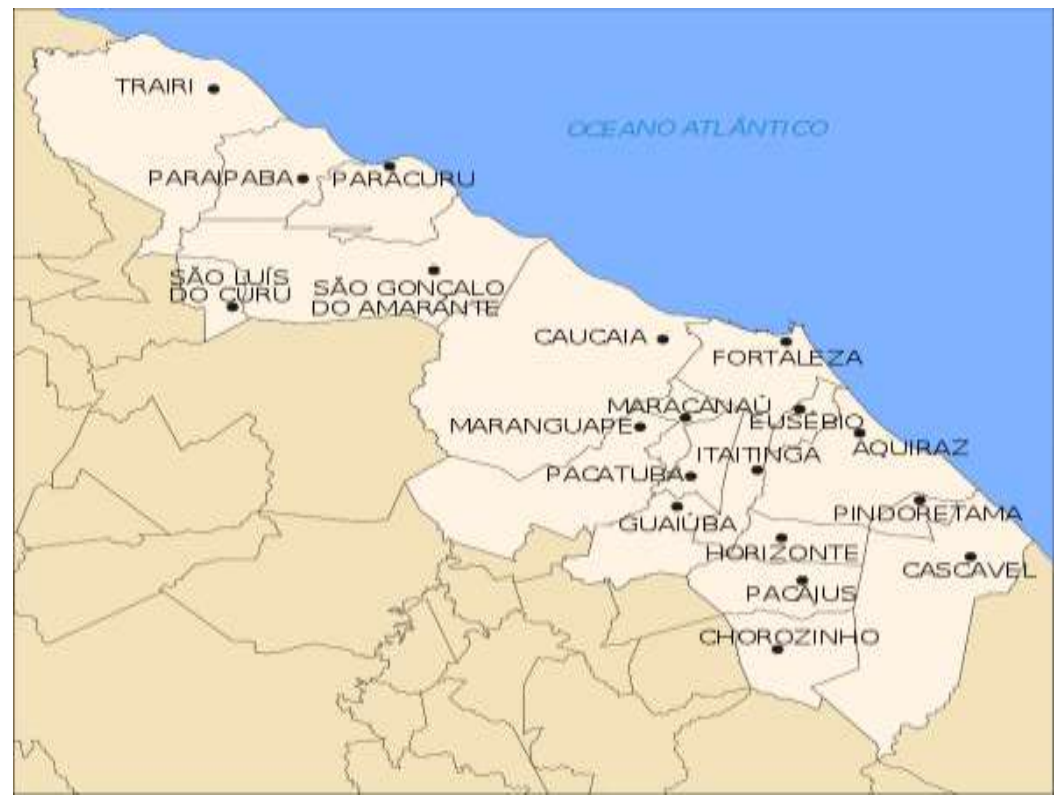

Fonte: Instituto Brasileiro de Geografia e Estatística (IBGE)

A cidade de Horizonte, no Estado do Ceará, é dividida em quatro regiões administrativas: sede do município, distrito de Dourado, Queimadas e Aningas, conforme podem ser observados no mapa abaixo.

consonância com as necessidades do indivíduo que teve seus direitos transgredidos? E mais, estamos falando de crianças e adolescentes que são estupradas, que sofrem agressões físicas, psíquicas, negligenciadas, que passam privações as mais diversas possíveis.

${ }^{12}$ Fonte: Instituto Brasileiro de Geografia e Estatística (IBGE). 
Figura 2: Mapa do município de Horizonte/CE e sua divisão política.

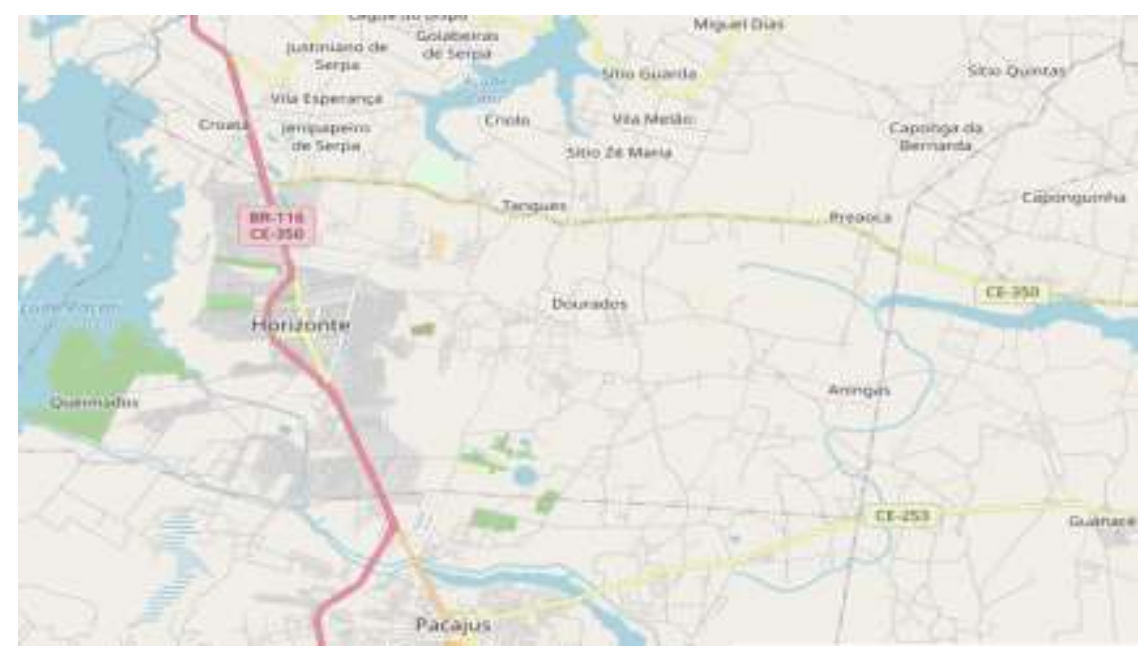

Fonte: https://www.cidade-brasil.com.br/mapa-horizonte.html

Os conselheiros tutelares advêm da classe social menos favorecida da população do município de Horizonte, com pouca escolaridade, e que procuram galgar uma melhor ocupação, com melhores dividendos para seu sustento e o provimento da sua família. E observaram que a função de agente social tutelar, denominação cunhada por Jacques Donzelot (2001) para caracterizar profissionais que trabalham com questões sociais, um canal, entre outros objetivos, para minorar as violações de direitos de crianças e adolescentes do município de Horizonte/CE, também vivido por eles.

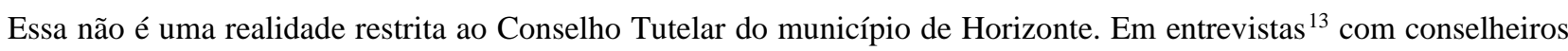
tutelares dos municípios das cidades ${ }^{14}$ de Fortaleza, Maracanaú, Caucaia, Eusébio e Pacajús, os quais foram candidatos ao posto do legislativo municipal na última eleição e quando indagados sobre o que motivaram a candidatura ao CT, $63 \%$ dos entrevistados apontaram a oportunidade do emprego e, em segundo lugar, 37\% responderam a possibilidade da formação da carreira política partidária.

Aos $63 \%$ dos entrevistados foi perguntado se possuíam vontade de seguir a carreira política partidária. Entre estes, 94\% afirmaram que esse também era um dos objetivos a ser delineado, mas que essa "vontade política" só apareceu quando adentrou o espaço tutelar. Nesse sentido, tanto a ocupação da função temporária em estar conselheiro tutelar, bem como a formação da sua carreira política partidária fazem parte dos principais objetivos almejados pelos entrevistados.

Portanto, a função de conselheiro tutelar, levando em consideração esse primeiro dado tem seu embrião na alocação de trabalho. Enquanto que a atmosfera da defesa dos direitos infanto-juvenis aparece para esses cidadãos como fator periférico. Apropriando-se criticamente desse dado, é confirmado porque esses cidadãos possuem pouco ou quase nada em termos de conhecimento referendado às questões que envolvem o universo infanto-juvenil. Uma vez que, indagados se possuíam algum trabalho ou conhecimento institucionalizado sobre crianças e adolescentes, antes de se candidatarem a função tutelar, $92 \%$ dos entrevistados disseram que não possuíam.

Portanto, 37\% dos cidadãos que embora possuíssem ocupação/emprego, se utilizaram, mesmo antes de adentrar o espaço do CT e do cargo de conselheiro tutelar para promover-se com vistas a galgar notoriedade para as eleições municipais. Para Lefebvre (1973) o espaço social é constituído de elementos importantes, logo, objeto político utilizado por aqueles que

\footnotetext{
${ }^{13}$ As entrevistas foram realizadas por telefone no mês de maio do ano de 2021, tendo em vista a impossibilidade de estar presente no lócus de atuação dos conselheiros tutelares por causa do contexto e os imperativos da pandemia do Sars-Cov-2, popularmente chamado de coronavírus. Ao todo foram quase sessenta entrevistas realizadas por telefone.

${ }^{14}$ Todas essas cidades fazem parte da Região Metropolitana de Fortaleza, capital do Estado do Ceará: Fortaleza, Maracanaú, Caucaia, Eusébio, Pacajús e, no caso estudado, o município de Horizonte.
} 
querem chegar ao poder e sua hierarquia. Assim, a eleição ao cargo de conselheiro tutelar, em um grande número de casos, como veremos a frente, tem como objetivo tornar-se um trampolim para obter visibilidade e popularidade ${ }^{15}$ para, depois, candidatar-se ao cargo de vereador nas eleições proporcionais na Cidade. Além de passar pela experiência de uma eleição, mesmo que não obrigatória, como é o caso da eleição ao $\mathrm{CT}$, torna-se uma espécie de simulacro eleitoral onde se tem na rua carros de som com seus jingles, o denominado "santinhos" com a foto do candidato, pessoas nas ruas no denominado porta a porta atrás de angariar votos. Todo esse processo se configura como um ensaio para a campanha eleitoral proporcional, afirmando a tese que o CT possui elementos cruciais para a formação da carreira política partidária.

Um dado importante encontrado nas entrevistas nos $92 \%$ dos que almejavam a carreira política partidária foi que essa "vontade política" só apareceu quando estavam atuando no CT. Na medida em que realizavam o trabalho tutelar, os pretensos candidatos adquiriam uma relação com um grande número de pessoas nos diversos bairros do município. Na linguagem bourdieziana, estava criando um capital social ${ }^{16}$ que é o principal elemento para que dispusessem seu nome ao pleito legislativo. Ademais, como muitos mencionaram em suas respostas, era frase comum dita pela população, à vontade de que eles se candidatassem a função pública de vereador na cidade.

A ideia de ser candidata à vereadora era muito distante, mesmo possuindo pouca vontade. Porque a gente escuta falar que precisa de tantos reais para se eleger [...] sair candidato a vereador ou prefeito é difícil por quem não possui dinheiro não vence. Mas aí a gente "ajudava" as pessoas e elas sempre diziam: "por que você não se candidata ao cargo de vereadora? Você é uma pessoa tão boa e ajuda tanta gente, garanto que você ganha." Foi a partir daí que eu comecei a colocar na cabeça que era possível sair candidata e ganhar porque muita gente estaria ao meu lado. Foi assim que surgiu o interesse em sair candidata na última eleição. E assim fui com a ajuda da população [...] principalmente das pessoas que "ajudei" através do Conselho Tutelar. (Depoimento de uma conselheira tutelar que foi candidata à vereadora na cidade de Fortaleza, Capital do Ceará, no pleito de 2020).

De fato, o cargo de conselheiro tutelar traz uma proximidade com famílias fragmentadas (Roudinesco, 2003), que veem seus direitos sociais sendo dilacerados pelos entes governamentais. Situação que abre espaço para o oportunismo daqueles que buscam arregimentar adeptos a sua candidatura. Segundo Leal (2012, p.44), "a situação de dependência e subjugação das pessoas é incontestável" diante de uma estrutura socioeconômica na qual estão inseridas. Assim, tornam-se "presas fáceis" para aqueles que dispõem de poder político local.

As pessoas que procuram os serviços do CT ainda veem a atuação dos conselheiros tutelares como que sendo um favor, ou como diz o antropólogo Mauss (1989), uma dádiva, e se veem numa situação de "pagar" - contra dádiva por tal serviço prestado. Bobbio (2000) vai dizer que uma das condições indispensáveis para o funcionamento da democracia é que as pessoas tenham as reais condições de poder escolher entre uma e outra opção. E o que se observa é que as condições ou realidade objetivas (Lessa, 1996) de existência da população, seu entrelaçamento contextual, fatores socioeconômico ${ }^{17}$ influenciam para que as mesmas sejam facilmente manipuladas quando em contexto de vulnerabilidade (Santos, 2018, p.35).

\footnotetext{
15 A principal característica da política, a partir de Maquiavel (2004), é a constante luta e conflito pelo poder. E o que os conselheiros tutelares realizam, paralelo, ou até mesmo implicado em suas ações cotidianas são disputas de poder, em outras palavras, política. A busca por obter meios para galgar cargos no poder legislativo ou mesmo executivo vem demonstrar o que há muito se sabe a partir da teoria política, de que o povo também tem sede pelo poder.

16 “[...] o capital social é o conjunto de recursos atuais ou potenciais que estão ligados à posse de uma rede duradoura de relações mais ou menos institucionalizadas de interconhecimento e de inter-reconhecimento ou, em outros termos, a vinculação a um grupo, como conjunto de agentes que, além de serem dotados de propriedades comuns (passíveis de serem percebidos pelo observador, pelos outros ou por eles mesmos), estão unidos por ligações permanentes e úteis" (BOURDIEU, 1980, p.2).

${ }_{17}$ O que foi garantido na Constituição Federal de 1988 está muito longe da realidade. A mesma garante educação, saúde, alimentação, trabalho, moradia, transporte, lazer, segurança, previdência social, proteção à maternidade e à infância, assistência aos desamparados, entre outros. Isso é obrigação do Estado Democrático de Direito, e na ausência destes os cidadãos se veem reféns daqueles que possuem poder político e econômico local. Logo, a não concretização dos princípios constitucionais também se configuram em um fator que resvala na subserviência da população corroborando com o "mandonismo, o filhotismo, o falseamento do voto, a desorganização dos serviços públicos locais" (LEAL, 2012, p. 44). E isso é constatado quando o agente Legislativo executa algumas funções no cotidiano que não dizem respeito as suas prerrogativas legais: disponibilizando matérias de construções, intermediando consultas e cirurgias médicas, doando cestas básicas entre outras necessidades.
} 
A guisa de respostas, o Conselho Tutelar proporciona desde a sua eleição e atuação grande visibilidade pública. São eventos diários nos espaços públicos onde aparecem para a população como "autoridades" do município. Constrói-se o retrato sociopolítico do conselheiro tutelar como sendo um sujeito que possui poder por tramitar nos mesmos espaços que vereadores, prefeitos e representantes do judiciário ${ }^{18}$.

O capital simbólico vai sendo construído a partir da relação com os representantes públicos com cargo eletivo, bem como com o trabalho assistencialista que possuem diante dos problemas que envolvem a vida de criança, pais ou responsáveis. Temos, também, o reconhecimento da notoriedade do conselheiro tutelar, onde a população passa a julgar e reconhecer (julgar moralmente e capacidade técnica) a função que exerce. Mas é importante destacar que esse acúmulo simbólico de poder e prestígio começam a acontecer a partir do momento que os mesmos conseguem se eleger a função, pois como demonstra a resposta de um entrevistado:

Quando eu ganhei a eleição ao cargo de conselheiro tutelar, as pessoas passaram a me tratar da mesma maneira como se eu fosse um político com mandato (menção ao mandato eletivo de vereador). É verdade que minha função possui um mandato eletivo, mas eles (menção a população) pensam que recebemos o mesmo dinheiro (menção ao salário) dos vereadores [...] muitos que votaram em mim pedem dinheiro, bola de futebol, camisas de time, cestas básicas como se eu fosse vereador e tivesse condições de arcar com isso. Mal sabem eles que recebo um salário bem baixo. E quando digo o quanto recebo (menção ao salário de conselheiro tutelar) eles não acreditam. Muitos ficam até com raiva de mim. (Depoimento de um conselheiro tutelar do município de Maracanaú, no Estado do Ceará, que foi candidato a vereador no pleito de 2020).

Dessa forma, o CT possui elementos indispensáveis para quem quer transpor essa pirâmide social do poder. Por trazer visibilidade pública e poder político ao estar próxima de um grande número de pessoas que aos olhos de Bourdieu (1989) tornam-se indivíduos com grande potencial agregador de voto, isto é, com grande capital social e político, esse espaço confere aos agentes tutelares essa possibilidade de ascensão em uma arena política marcada pelo domínio das elites locais.

É necessário salientar, mesmo discorrido anteriormente, que o perfil dos que se candidatam ao posto de agente tutelar são pessoas da classe baixa da sociedade. Isso porque o salário conferido a este é pouco se comparado com a função social que lhe compete. Desde as formulações das leis e diretrizes do Estatuto da Criança e do Adolescente (ECA/90), no que se refere ao dividendo salarial dos conselheiros tutelares foi/é algo que se deixou "solto", a cargo de qualquer valor imposto pelo executivo municipal. Há indícios e confirmações de que agentes tutelares, em algumas cidades do interior do Estado do Ceará, recebem um valor mensal abaixo de um salário mínimo. Decerto, esse é um dos motivos que esse posto é disputado por indivíduos das camadas menos favorecidas da sociedade. Para isso, basta observar o perfil dos dois casos dos conselheiros tutelares desse estudo.

Dito isso, quem faz parte da elite local não possui interesse em ser conselheiro tutelar, mesmo sabendo que esse campo possui elementos os quais são fundamentais para arregimentar um grande número de votos. Assim, abre-se espaço para que indivíduos vindos da classe menos favorecida, conjugando com relações intrínsecas do CT possam vislumbrar ascensão social através da formação de carreira política partidária.

\footnotetext{
${ }^{18}$ A aparição pública dos conselheiros tutelares vai performatizar a imagem de "autoridade". Além disso, sua rede de conexões irá ampliar com a aproximação com políticos com mandatos eleitorais, como vereadores e prefeitos, bem como representantes do Ministério Público (MP).
} 


\subsection{Casos analíticos: "táticas” para se chegar ao poder político partidário}

\section{Caso I}

Quando Erisvaldo de Sousa Nascimento (E.S.N.) ${ }^{19}$, conhecido popularmente como "Haroldo da Saúde", por já ter trabalhado na função de agente de endemias, por breve três anos, adentrou o espaço do conselho tutelar, em 2010, não possuía a dimensão que o espaço tutelar poderia conferir-lhe para a formação da sua então carreira política partidária.

Hoje, analisando o que passei no Conselho Tutelar, vejo que comecei a ganhar voto a partir da eleição ao cargo. As pessoas se envolviam mesmo (falava enfaticamente) na disputa [...] lembro como se fosse hoje, quando estava fazendo o porta a porta, as pessoas foram vindo atrás de mim, uma por uma até que formou uma multidão de gente que não sei de onde saiu e assim formou uma caminhada igualmente de campanha para prefeito (nesse momento, sorriu). Mas quando eu estive atuando no CT (abreviação nossa) foi que eu percebi que a partir dele dava para disputar (menção a disputa política partidária a candidatura a vereador). Primeiro porque a gente (conselheiro tutelar) ajuda muitas pessoas com problemas tão delicados que eles ficam emocionados, muitos até choram. Isso me comove e marca a pessoa para o resto da vida. O CT possui algo diferente dos outros lugares de trabalho (Depoimento do ex-conselheiro e atual vereador do município de Horizonte, Estado do Ceará, Erisvaldo de Sousa Nascimento).

Como mencionou E.S.N., “o CT possui algo diferente dos outros lugares de trabalho”, este lugar, conferido ao Conselho Tutelar (CT) deve ser trabalhado de maneira enfática e especificamente, algo que até então não si vê na bibliografia das pesquisas conferidas aos conselhos. Além disso, há um ato de confundir-se entre os conselhos setoriais (como da mulher, do idoso, da criança, da juventude, do orçamento participativo) com o espaço do conselho tutelar. Não muito raramente, vemos esse embaraço nas disposições sobre a literatura referente aos conselhos.

A individualidade e singularidade de que fala o ex-conselheiro e atual vereador do município de Horizonte, E.S.N., está no fato de que o CT é um espaço autônomo - e por autônomo, já dito acima, não confere subordinação a ninguém - pois foram eleitos pela população, mas sua atuação está conferida nos limites dos dispositivos normativos do ECA/90. Além disso, os conselheiros tutelares devem receber uma remuneração mensal, conforme criado por lei municipal, ao mesmo tempo em que possuem carga horária semanal. Realizam intervenções quando ocorrem violações de direitos das crianças e dos adolescentes em qualquer espaço do município sem a interferência de ninguém (Brasil. Lei nº 8.069, 1990, art. 95, 101 (I a IV), 129 (I a VII) e 136).

Essas características devem estar bastante explícitas para que não imputem ao CT características e conjecturas que não lhes pertencem. Ademais, o fato do CT ser um espaço autônomo, de trabalho remunerado diário, de atuação interventiva, por si só, o torna peculiar quando comparado com os demais conselhos. A palavra "conselho" não pode ser utilizada para colocar todos os conselhos num mesmo pedestal.

Sob esse aspecto - sua singularidade - é que vai recair as ações - táticas - colocadas em prática por E.S.N. para construir sua carreira política partidária eleitoral. Por trabalhar com problemas sociais de foro íntimo da população menos favorecida da cidade, que requer sigilo inconteste (Art.17 do ECA/90), surge uma relação afetiva. Diferentemente de muitos espaços públicos, o trabalho que é desenvolvido no CT transborda o lado público adentrando a esfera privada e foi a partir dessa característica que o E.S.N. fez uso para ampliar sua rede de contatos.

Passei a fazer visitas todos os dias. As pessoas querem que o político esteja na casa delas, perto dela, com elas: escutando, conversando, tomando café. E fiz isso todos os dias quando estava no CT [...] e quando estava na casa delas, pegava o número do WhatsApp, endereço e ainda perguntava se possuíam mais familiares e onde moravam porque eu queria e necessitava conhecer mais gente. Quanto mais, melhor. (Depoimento do ex-conselheiro tutelar e hoje vereador do município de Horizonte, Estado do Ceará, Erisvaldo de Sousa Nascimento).

${ }^{19}$ Utilizaremos as siglas E.S.N. para referir-se ao ex-conselheiro tutelar e hoje vereador e agente público do município de Horizonte, Erisvaldo de Sousa Nascimento, no Estado do Ceará. 
Como pode ser compreendido, E.S.N. se comportava como um sujeito político profissional, mesmo sem mandato eletivo eleitoral partidário. Contudo, suas ações e visões na função de conselheiro tutelar eram de alguém que já se manifestava com essa intenção, de ser político partidário. Para isso, utilizou-se da aproximação afetiva que o CT cria e da ferramenta do WhatsApp para aproximar-se e não perder o contato com os seus pretensos eleitores. E.S.N. possuía um caderno com os nomes das pessoas que passou a ter contato e como essa ferramenta ajudou a manter a proximidade entre ele e os sujeitos que eram atendidos pelo CT.

O CT possui seu caderno de anotações diárias das pessoas que são atendidas. Mas eu criei a minha. Tinha um caderno só para anotações das pessoas que começava a criar um elo, uma ligação. Foi importante porque não podia perder essas pessoas "de vistas" (menção a estar próximo). E priorizava essas pessoas no atendimento, dando total atenção porque eu precisaria delas futuramente [...] como tinha o whatsApp delas, enviava mensagem em dias festivas e comemorativos: dando parabéns, entre outras coisas [...] (Depoimento do ex-conselheiro tutelar e hoje vereador do município de Horizonte, Estado do Ceará, Erisvaldo de Sousa Nascimento).

A criação de grupos de prioridade de atendimento do CT, também é uma estratégia para criar e ampliar sua rede de contatos. Dessa forma, partindo da criação de tipos ideias weberianos, criamos o seguinte esquema de atendimento para ilustrar o que E.S.N. realizava nos seus atendimentos:

Figura 3 - Criação dos grupos de prioridades de atendimentos no Conselho Tutelar.

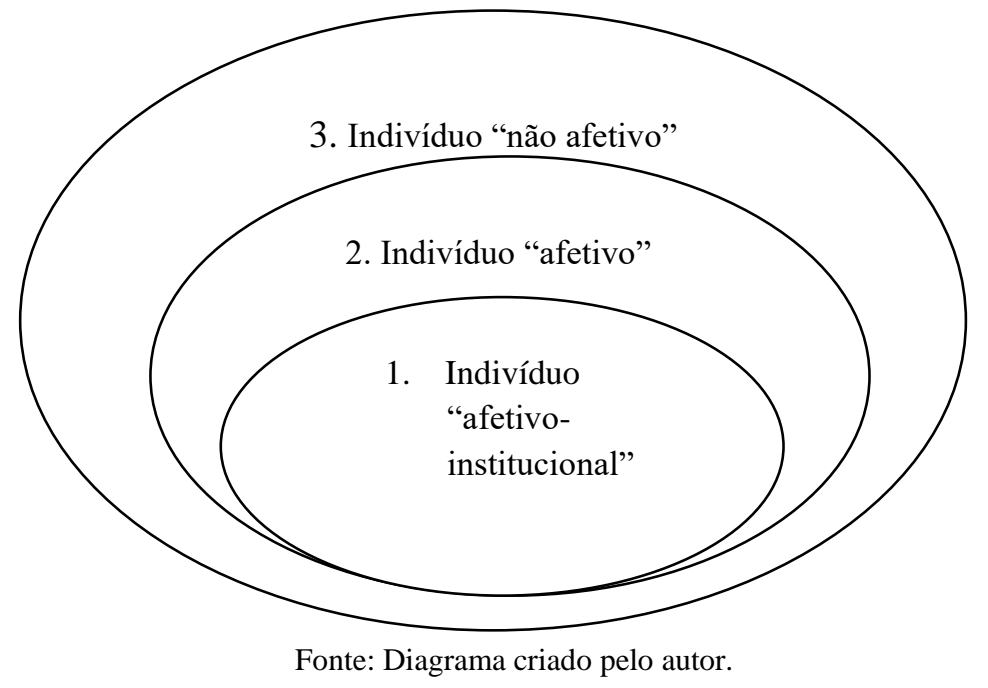

A partir das informações fornecidas por E.N.S., foi-nos possível classificarmos e denominarmos os sujeitos que necessitam do trabalho do agente social tutelar, independente do conteúdo que os fazem requerer a mediação dos conselheiros a partir das "relações de afetos", já que essa relação foi criada a partir de bases não materialistas ${ }^{20}$.

A prerrogativa que deu margem para esta formulação tem esteio nas motivações que orientam a busca da ação tutelar e a relação mantida com o conselheiro, com o objetivo de compreender quem são os atores sociais que corriqueiramente agem no espaço do CT conforme os interesses e objetivos do agente social.

Como demonstra o esquema acima, no centro das atenções do conselheiro tutelar estão os sujeitos que figuram no primeiro grupo, denominado de "afetivo institucional". Estão neste grupo: políticos locais, tanto do Poder Executivo quanto do Legislativo municipais, bem como pessoas que fazem parte da administração local, como secretários municipais e assessores

${ }^{20} \mathrm{O}$ trabalho do conselheiro tutelar está na dimensão pedagógica da fala e da intervenção com base em encaminhamentos quando das situações que transbordam suas atribuições, encaminhando para outros órgãos/instituições que mobilizam o arsenal de ações para "remediar" os possíveis direitos violados das crianças ou adolescentes. 
destes. Já os indivíduos do segundo grupo, denominados de "afetivos" são aqueles sujeitos que começam a fazer parte da formação do círculo do círculo afetivo do conselheiro tutelar: estes, futuramente, serão eleitores daquele. São, também, pessoas que possuem relações de amizade, cordialidade e proximidade com o mesmo. Restam, pois, no terceiro grupo, os denominados "não afetivos". Neste grupo figuram todos os indivíduos que fazem parte de grupos políticos de algum vereador que não trará dividendo positivo para a formação e eleição política partidária do conselheiro tutelar.

Importante destacar o primeiro grupo de atendimento prioritário, ou seja, "os individuos afetivos institucionais", pois, como o E.S.N. nos informa, serão importantes instrumentos para a ampliação da sua rede de contatos e, consequentemente, da sua carreira política eleitoral.

A partir do $\mathrm{CT}$ a gente tem proximidade com todas as secretarias do poder executivo. E isso foi muito bom porque ajudei muita gente. Mesmo não sendo nosso trabalho (menção ao trabalho do conselheiro tutelar), quando eu ia fazer visitas e as pessoas me viam não só como conselheiro, mas também como um político profissional (já foi mencionado acima), elas pediam coisas, como dentadura, bola de futebol, terno de time, passagens para outros municípios, exames médicos, material de construção e muitas outras coisas [...] eu só poderia conseguir isso com a proximidade com o poder executivo e com os secretários [...] eu era amigo de todo mundo porque sabia que precisava, pois não tinha dinheiro para arcar com isso. (Depoimento do ex-conselheiro tutelar e hoje vereador do município de Horizonte, Estado do Ceará, Erisvaldo de Sousa Nascimento).

Isto implica, conforme Bourdieu (2004), que o capital social que o conselheiro tutelar, E.S.N. criava, estava ampliando à medida que esses elos iam ganhando ramificações. A relação com "sujeitos afetivos institucionais" só foi possível pela função que executava como conselheiro tutelar que foi imprescindível na relação que mantinha com seus pretensos eleitores.

Com efeito, a partir da relação que mantivera com as pessoas que necessitavam das atribuições do CT, conjugada com o elo que criava com os espaços institucionais, E.S.N. candidatou-se a vereador em 2012, sendo eleito em primeiro lugar com $1.928^{21}$ votos.

\section{Caso II}

Em 2020, temos o caso do conselheiro tutelar que hoje exerce o mandato de vereador, Edson Carlos de Almeida (E.D.A $)^{22}$, que fazia parte do colegiado do conselho tutelar do município de Horizonte, Estado do Ceará. Em entrevista, E.C.A. disse que um "bom candidato a conselheiro não se reelege e não cria as condições para sair candidato a vereador". Indagado sobre o que seria, na visão dele, "um bom conselheiro tutelar", E.C.A. respondeu:

É o conselheiro tutelar "superman" (em referência ao herói em quadrinhos que salva as pessoas que necessitam de ajuda) [...] são os conselheiros tutelares que trabalham de acordo com ECA/90 [...] são aqueles que vão contra a administração pública (em referência ao poder público do executivo municipal), que entra com ação no Ministério Público (MP) e fica sendo perseguido ("perseguido" pela administração do executivo municipal). Pode ter certeza que esse conselheiro não ganha nem para a reeleição ao CT. (Depoimento do ex-conselheiro tutelar e hoje vereador do município de Horizonte, Estado do Ceará, Edson Carlos de Almeida).

Ser "um bom conselheiro tutelar", para o atual vereador E.C.A., é aquele conselheiro tutelar que realiza as atribuições que competem à função conforme o Estatuto da Criança e do Adolescente (ECA/90). Muitos problemas de violações que envolvem crianças e adolescentes advêm do Estado na figura do poder público do executivo municipal. São escolas que não

${ }^{21}$ Conforme o Tribunal Superior Eleitoral (TSE), o candidato eleito em 2012, Erisvaldo de Sousa Nascimento, mais conhecido popularmente como "Haroldo da Saúde", obteve 1.928 votos que perfazem 4,99\% dos votos apurados no município de Horizonte, Estado do Ceará.

${ }^{22}$ Utilizaremos as siglas E.C.A. para referir-se ao ex-conselheiro tutelar e hoje vereador do município de Horizonte, Estado do Ceará, Edson Carlos de Almeida, popularmente conhecido como "Edson Papinha". 
possuem matrículas; falta de medicamentos e realização de exames e procedimentos cirúrgicos; assistência a crianças e adolescentes que necessitam de alimentação para a sobrevivência, entre outros casos. Nesse momento, o conselheiro tutelar é instigado a realizar procedimentos mais enérgicos com relação ao poder público local que possui o dever de cumprir com suas obrigações protetivas.

Muito raro ocorre uma intervenção em nível de Ministério Público (MP) e realizam-se ações paliativas, não suprindo as reais necessidades dos sujeitos implicados em questão. Com esse registro de ações em mente, E.C.A. procurou realizar táticas que não medisse forças com o poder público do executivo local. Pelo contrário, comportou-se, como veremos no próximo depoimento, como um agente a serviço do poder público local, bem mais do que os interesses infanto-juvenis violados.

Eu sempre soube que precisava do prefeito. E quem é o doido que vai se meter com ele? Ao invés de "brigar" eu fiz foi amizade porque precisava de alguma ajuda dele para o que almejava [...] antes de ser conselheiro tutelar nunca tive a oportunidade de estar ao lado do prefeito nos eventos, escutando no gabinete da prefeitura e isso nos aproximou. (Depoimento do ex-conselheiro tutelar e hoje vereador do município de Horizonte, Estado do Ceará, Edson Carlos de Almeida).

O Conselho Tutelar (CT), na visão e a partir dos objetivos que buscava concretizar, para E.C.A., era fundamental se comportar como agente a serviço do interesse do poder público local, sendo, portanto, um prolongamento dos interesses políticos locais. Fato esse comprovado quando o interesse central daqueles que deveriam ser protegidos são deixados de lado, entrando em cena interesses exteriores ao lócus de atuação, por exemplo, a formação da carreira política partidária.

Munido da idéia de não estar em conflito com nenhum sujeito, quer seja a população de modo geral, bem como o poder público, nas diferentes esferas, E.C.A., juntamente com os demais colegas do colegiado, perceberam que mediar conflitos na comunidade onde mora provocava uma ação que poderia perder o afeto das pessoas que há anos conhecia. Esse fato despertou o interesse de formular uma nova dinâmica metodológica de atuação tutelar não existente no Estatuto da Criança e do Adolescente (ECA/90) e até então não visto na literatura de pesquisas relacionadas às ações dos conselheiros tutelares.

Isto implicou, portanto, na configuração de um modelo de atuação onde o conselheiro tutelar "A" que reside na comunidade X, não poderia realizar intervenções nesta, mas sim, na comunidade Y. Assim como o conselheiro tutelar "B", que reside na comunidade $\mathrm{Z}$, não poderia realizar intervenções nesta, mas sim na comunidade $\mathrm{Y}$, onde residia o conselheiro tutelar "A".

Esse modelo de atuação visava sanar problemas como a inércia, ou possível negligência dos conselheiros tutelares, tendo em vista que no cotidiano se deparavam com conflitos intrafamiliares onde os implicados eram sujeitos que conheciam desde a infância e, que, por isso, possuíam uma relação afetiva. Por exemplo, ao se depararem com um possível estupro de vulnerável intrafamiliar cometido pelo pai em relação à filha/fillho, por morar na mesma comunidade e conhecê-lo desde a infância, muitos conselheiros se viam, nas palavras de E.C.A. num "fogo cruzado" porque era amigo tanto da mãe da criança, quanto do pai.

Essa situação de resolver problemas com pessoas que a gente viu crescer e se conhece é muito ruim. Às vezes eu ficava sem saber o que fazer porque as duas partes eram meus amigos [...] quando chegava algum problema da comunidade onde morava, já tinha deixado o aviso que não iria em hipótese alguma, pois iria me prejudicar lá na frente (referência a sua vontade em ser candidato a vereador). Daí tivemos essa ideia de enviar o conselheiro tutelar que não conhece os sujeitos em conflito, algo que passou a dar certo até então (Depoimento do ex-conselheiro tutelar e hoje vereador do município de Horizonte, Estado do Ceará, Edson Carlos de Almeida). 
Essa metodologia de atuação vai de encontro com a própria existência do Estatuto da Criança e do Adolescente (ECA/90) referente à escolha dos conselheiros tutelares. De acordo com Pinheiro (2006), os membros do CT pertencerem à comunidade está ancorada no conhecimento que eles possuem dos problemas de onde moram porque conhecem os sujeitos com quem convive. Contudo, na prática, empiricamente testado pelos conselheiros a partir do depoimento do E.C.A., ao invés de ajudar, dificulta a intervenção. Mas agora, depois de implantarem uma metodologia de atuação que, na visão dos membros, estava obtendo dividendos positivos na resolução dos casos, se deparam com novas questões:

Quando tocava o telefone do CT, as pessoas que estavam ligando chamava logo o conselheiro "X" ou o conselheiro "Y" porque o conhecia e só queria aquele conselheiro para estar a frente da intervenção. Quando era da comunidade onde eu resido, combinávamos que não estava presente e ia outro colega de trabalho porque a relação afetiva atrapalhava a intervenção [...] a partir daí começaram a surgir os "boatos" que eu não trabalhava porque não me viam na comunidade e assim ocorria com todos os demais membros do colegiado. (Depoimento do ex-conselheiro tutelar e hoje vereador do município de Horizonte, Estado do Ceará, Edson Carlos de Almeida).

Estes são problemas metodológicos que emergem repercussões na imagem do conselheiro tutelar e futuro pretenso vereador ou prefeito da cidade. E.C.A. pontuou que só observa mais benefícios do que pontos negativos nessa nova metodologia de intervenção, visto que sua imagem poderia ser odiada por uns, e amadas por outros.

Quero que todos gostem de mim e não somente alguns. Cito o exemplo de conflito entre marido e mulher onde a guarda do filho ficou com o pai porque a mãe era negligente. De posse do resultado da sentença, a mãe da criança passou a me odiar e o pai a me respeitar porque fui eu quem "cuidou" do caso. Mas passado algum tempo, os dois reataram o relacionamento e a mãe da criança nem queria me ver e ainda proibiu o marido de ter algum contato comigo. Ou seja, perdi dobrado com essa intervenção. (Depoimento do ex-conselheiro tutelar e hoje vereador do município de Horizonte, Estado do Ceará, Edson Carlos de Almeida).

Essa metodologia, além de ser uma estratégia de atuação do conselho tutelar com resultados positivos para a resolução de problemas que envolvem violações dos direitos infanto-juvenis, também se configura como sendo uma tática política eleitoral para não perder potenciais eleitores. Mas é importante salientar que estamos trabalhando empiricamente com uma cidade com cerca de quase 70 mil habitantes, onde, ainda, perduram laços de sociabilidade entre os vizinhos. Logo, essa metodologia é viável em cidades mais afastadas das capitais, com uma população mais reduzida, onde os moradores se conhecem. Diferentemente das grandes metrópoles e cidades do país que possuem milhões de moradores.

Perseguindo os passos das táticas colocadas em prática pelo E.C.A., em 2020 candidatou-se a função pública de vereador e obteve êxito ao ser eleito com 968 votos $^{23}$. Depois de duas eleições onde obteve êxito ao CT do município de Horizonte, Estado do Ceará, E.C.A. consegue a função pública de vereador na sua primeira disputa ao legislativo municipal.

Conforme consta nos registros do Tribunal Superior Eleitoral (TSE) e obtido através de entrevistas, em 2020, dos cinco conselheiros tutelares do município de Horizonte, Estado do Ceará, três (3) se candidataram ao cargo de vereador, isto é, 60\% dos agentes sociais tutelares da cidade. Entre estes estão, Edson Carlos de Almeida (E.D.A.) eleito com 968 votos; Adriana Silveira, que compõem o atual colegiado, obteve 697 votos $^{24}$, porém não eleita e o conselheiro Luiz Flávio Muniz que no decurso do processo eleitoral, abandonou a candidatura, se aliando a um candidato que obteve êxito no pleito.

\footnotetext{
${ }^{23}$ Conforme o Tribunal Superior Eleitoral (TSE), o candidato eleito em 2020, Edson Carlos de Almeida, mais conhecido popularmente como "Edson Papinha", obteve 968 votos que perfazem 2,16\% dos votos apurados no município de Horizonte, Estado do Ceará.

${ }^{24}$ É importante destacar que a conselheira tutelar do município de Horizonte, Estado do Ceará, Adriana Silveira, nas eleições proporcionais para vereadores na cidade, em 2020, obteve 697 votos, bem mais que dois candidatos que foram eleitos, são eles: "Irmão Bento" que obteve 647 votos e "Flávio da Coelce" que obteve 580 votos nas eleições proporcionais em 2020. A conselheira tutelar não obteve êxito por causa da legenda partidária. Se não fosse esse detalhe, os dois conselheiros tutelares tinham saído vitoriosos no último pleito, ou seja, 100\% dos candidatos conselheiros tutelares do CT do município de Horizonte, Estado do Ceará.
} 
Os demais conselheiros tutelares que não postularam uma vaga no legislativo municipal, geralmente passam a apoiar determinado candidato a vereador que possui mandato eletivo. Ou seja, há uma forte notoriedade dos conselheiros tutelares por parte dos vereadores e demais políticos, uma vez que estes são fontes para angariar votos a partir do campo do CT. Muitos dos conselheiros entrevistados, antes do pleito, até mencionaram a vontade de candidatar-se ao cargo de vereador. Contudo, ao chegar o momento da eleição política partidária proporcional, muitos deles são cooptados pelos candidatos - a grande maioria com mandatos eletivos - por vereadores da cidade.

\section{Considerações Finais: Tensionamento Entre o Conselho Tutelar e a Carreira Política Partidária}

Para entender a relação entre conselho tutelar e carreira política partidária faz-se necessário sair do senso comum que é corriqueiramente "escuta constante" nas conversas entre os indivíduos, abrindo a questão para uma reflexão aprimorada. Dito isto, como denominada acima, a análise que deve ser colocada em prática tem que ser tensionada no que diz respeito aos elementos que esse espaço oferece, os quais são fundamentais, quando bem utilizadas, para a formação da carreira política partidária.

A relevância do campo tutelar é regida pelos elementos que possui: simulacro eleitoral, relação afetiva a partir dos problemas de foro íntimo com famílias que necessitam do trabalho tutelar, bem como a aproximação com os espaços institucionais e estratégias metodológicas de atuação. Sem esses recursos que só o CT possui, não existiria a possibilidade da formação de uma carreira política partidária das pessoas das camadas menos favorecidas que adentram esse campo.

No que diz respeito ao simulacro eleitoral, os pretensos candidatos ao pleito para a câmara de vereadores, vivenciaram relações de aproximação igualmente conferidas aos de um pleito político partidário. Esse momento faz com que o postulante se adeque as necessidades do curso do pleito, ou, caso não se identifique com o contexto eletivo, desaproxime da ideia. A grande maioria dos que pleitearam e venceram as eleições ao CT, quando na função tutelar, passaram a almejar o pleito político partidário ao cargo de vereador. Dito isso, para os dois casos trabalhados nessa pesquisa, por não possuírem envolvimento com movimentos sociais, uma vez que o município não possui a tradição de associações desse gênero desde a sua emancipação política e administrativa, bem como não pertencerem a nenhum partido político, pois os mesmos não eram filiados até adentrarem o espaço do CT, faz com que os mesmos sejam denominados de outsiders.

Esses cidadãos que adentraram o espaço do CT eram da classe menos favorecida, com trabalhos "informais", como vendedor de roupas e calçados e, o outro, exercendo o trabalho de moto taxista. A primeira vontade que destoava quando foram candidatos ao CT antes de adentrar o campo tutelar era do emprego, mesmo que por tempo determinado, ou seja, quatro anos (tempo do mandato eletivo no Conselho Tutelar). Só depois de estarem na função de agente social, a partir do trabalho assistencialista, surgiu a vontade de concorrer à vaga ao legislativo.

Como os candidatos não possuíam dinheiro, se comparado aos seus adversários políticos, o que colocaram em prática foram os dividendos ganhos com o trabalhar tutelar. A rede afetiva que criaram, ao estar ao lado dos pretensos eleitores, utilizando-se de ferramentas como WhastApp, visitas domiciliares constantes e demandas obtidas através das relações "afetivas institucionais" com os órgãos e secretarias do governo municipal ajudaram a manter esse elo. Essa "rede afetiva" foi primordial para a obtenção do voto e, consequentemente, o êxito na campanha política partidária, destoando o imaginário de que só os candidatos que possuem dinheiro podem chegar ao poder político eleitoral.

As táticas colocadas em ação também ganharam notoriedade ao empregarem metodologia de atuação diferente daquela que o próprio ECA/90 preconiza que é o do conselheiro tutelar que conhece os vizinhos e a dinâmica da sociabilidade comunitária. Ao perceber que esse método não produzia o resultado esperado no que diz respeito à resolução dos conflitos, reconfigurou-se e implantou-se um método próprio até então não existente na literatura sobre o CT. Além disso, essa prática minora a possibilidade de ocorrer desafetos com pessoas que os conselheiros tutelares conhecem desde a infância. 
Dito isso, o campo Conselho Tutelar (CT) vive constantemente um ciclo. Bourdieu (2004), em algumas situações, chega a espantar-se sobre a ordem estabelecida, com suas relações de dominação, seus direitos e suas imunidades, seus privilégios e suas injustiças, apesar disso, perpetuando-se. Um ciclo, portanto, no Conselho Tutelar (CT) que se abre e fecha a cada quatro anos, como é a escolha do colegiado. Nesse momento, os eleitores são chamados a intervir, de forma não obrigatória, na escolha dos novos membros. Assim, é importante observar que as posições políticas e de figuras políticas são abstrações criadas para o entendimento desse campo que é construído ou reconstruído a cada recondução. A votação, obtida nessa eleição, é importante destacar isso, não reflete a votação das eleições políticas partidárias eleitorais. Mas esse campo não deixa de ser um importante criador de capital simbólico que passou a ser utilizado por pretensos candidatos a vereadores, por conselheiros tutelares, a partir dos elementos e repertório existente no mesmo, para a formação da sua carreira política partidária.

\section{Referências}

Becker, H. S. (2008). Outsiders: estudo da sociologia do desvio. Zahar.

Bourdieu, P. (2004). O poder simbólico. (4a ed.), Bertrando Brasil.

Bourdieu, P. (1989). Razões práticas: sobre a teoria das ações. Tradução de Mariza Corrêa. Papirus.

Bourdieu, P. (1990). Coisas ditas. Tradução de Cássia R. da Silveira e Denise Moreno Pegorim. Brasiliense.

Bourdieu, P. (1981). Sociologia. Organizado por Renato Ortiz. Ática.

Brasil. (1989). Constituição da República Federativa do Brasil promulgada em 1988. Brasília, Senado Federal.

Brasil. Lei n ${ }^{\text {8 }}$ 869, de 13 de julho de 1990. Diário oficial da República Federativa do Brasil. Brasília, DF, 16 jul. 1990. Art. 131.

Catani, A. F. (2017). Vocabulário Bourdieu. Autêntica editora.

Cortes, S. M. V. (1995). Participação de usuários nos conselhos municipais de saúde e assistência social de Porto Alegre. Mimeografado.

Cortes, S. M. V. (2007). Viabilizando a Participação em Conselhos de Politicas Públicas Municipais: Arcabouço institucional, organização do movimento popular e policy commuinities. In: HOCHMAN, G, ARRETCHE, M, \& MARQUES, E. (Orgs.). 2007. Políticas públicas no Brasil. Rio de Janeiro: Fiocruz.

Costa, J. F. (1989). Ordem médica e norma familiar. (3a ed.), Graal.

D'certeau, M. (2014). A invenção do cotidiano: artes de fazer. Editora Vozes.

Demo, P. (1981). Metodologia científica em ciências sociais. Atlas.

Demo, P. (2001). Cidadania pequena: fragilidades e desafios do associativismo do Brasil. Campinas, São Paulo: Autores Associados (Polêmicas do nosso tempo; 80).

Demo, P. (1991). Pesquisa: princípio científico e educativo. (2a ed.), Cortez.

Demo, P. (1994). Política social, educação e cidadania. Papirus.

Demo, P. (1995). Cidadania tutelada e cidadania assistida. Autores Associados.

Donzolet, J. (2001). A polícia das famílias. Graal.

Lefebvre, H. (1973). The survival of capitalism. Allison and Busby.

Leal, V. N. (2012). Coronelismo, enxada e voto. (7a ed.), Companhia das Letras.

Luciana, A. M. S. (2021). Partidos, governo e Legislativo nas disputas do Orçamento Participativo: uma análise comparativa. Revista Opinião Pública.154188. https://www.cesop.unicamp.br/vw/1I8PySqswNQ_MDA_71b43_/6\%20Partidos,\%20governo\%20e\%20legislativo\%20nas\%20disputas\%20 do\%20Or\% C3\%A7amento\%20Participativo.pdf >

Minayo, M. C. S. (2016). Pesquisa Social: teoria, método e criatividade. Vozes.

Moscovici, S. (1978). A representação social da psicanálise. Zahar.

Netto, J. P. (2001). Capitalismo monopolista e serviço social. (7a ed.), Cortez.

Pinheiro, Â. A. A. (2006). Criança e adolescente no Brasil: por que o abismo entre a lei e a realidade. Editora UFC. 
Research, Society and Development, v. 11, n. 1, e55911124796, 2022

(CC BY 4.0) | ISSN 2525-3409 | DOI: http://dx.doi.org/10.33448/rsd-v11i1.24796

Roudinesco, E. (2003). A família em desordem. Editora Zahar.

Rousseau, J. J. (1989). O contrato social. Contexto.

Santos, A. N. S. (2010). Família, Criança e Mudança Social: reconfiguração da sociabilidade intrafamiliar a partir da nova concepção da criança como sujeito de direitos. 79 f. Trabalho de Conclusão de Curso (Graduação em Ciências Sociais) - Centro de Humanidades, Universidade Federal do Ceará, Fortaleza. CD-ROM.

Santos, A. N. S. (2014). Do conflito à intervenção tutelar: um estudo sobre casos intrafamiliar e a intervenção dos Agentes Sociais do Conselho Tutelar e do CREAS frente a essa (des)ordem. 2014. 89 f. Trabalho de Conclusão de Curso (Graduação em Serviço Social) - Centro de Estudos Sociais Aplicados (CESA), Universidade Estadual do Ceará, Fortaleza, CD-ROM.

Santos, A. N. S. (2018). "Mal-estares e utopia democrática”: poder local e autonomia institucional - o caso do Conselho Tutelar do Município de Horizonte - Ceará. 138 f. Dissertação (Mestrado Acadêmico ou Profissional em 2018) - Universidade Estadual do Ceará, <http://siduece.uece.br/siduece/trabalhoAcademicoPublico.jsf?id=82831>

Santos, A. N. S. (2019). Mal-estar e utopia democrática: autonomia do conselho tutelar e as consequências das políticas públicas infanto-juvenil. Revista Instituto de Políticas Públicas de Marília. 5(2). 117-138. https://revistas.marilia.unesp.br/index.php/RIPPMAR/article/view/8993

Tatagiba, L. (2002). Os conselhos gestores e a democratização das políticas públicas no Brasil. Paz e Terra. 